\title{
Massive transient pulmonary air embolism during transvenous pacemaker implantation: potentially lethal but avoidable complication
}

\author{
Naveen Chandra Ganiga Sanjeeva, Padmakumar Ramachandran, Jwalit Morakhia, \\ Ganapathiraman Vivek
}

Department of Cardiology, Kasturba Medical College, Manipal University, Manipal, Karnataka, India

\section{Correspondence to}

Dr Naveen Chandra Ganiga Sanjeeva, drnaveenchandrags@ gmail.com

Accepted 8 September 2014

\section{CrossMark}

\section{To cite: Ganiga}

Sanjeeva NC,

Ramachandran $\mathrm{P}$,

Morakhia J, et al. BMJ Case Rep Published online:

[please include Day Month

Year] doi:10.1136/bcr-2014

207053

\section{DESCRIPTION}

A 71-year-old male patient presented to us with a history of repeated episodes of syncope. On evaluation, he was found to have complete heart block, for which we decided to go ahead with transvenous dual chamber pacemaker implantation. We went ahead with the extrathoracic subclavian venous puncture for endocardial lead insertion. Once the lead was introduced via the $7 \mathrm{~F}$ peel away sheath, patient had sudden onset of respiratory distress with desaturation. On fluoroscopy we noticed massive amount of air inside the right ventricular outflow tract and pulmonary artery (figure 1 and video 1) suggestive of iatrogenic air embolism. Opening and closing of the pulmonary valve could be appreciated in fluoroscopy (video 1). Immediately the patient was started on $100 \% \mathrm{O}_{2}$ via mask for $10 \mathrm{~min}$. Patient completely recovered and vitals became stable with disappearance of air in the pulmonary artery, hence the procedure was completed (figure 2).

Accidental air embolism during percutaneous venous puncture is a potentially lethal but avoidable condition. Intrathoracic pressure variation in central veins in different phases of respiration causes a sucking effect during the inspiration which mostly results in accidental air embolism. Some predisposing factors are chronic obstructive airway disease, frequent coughing during procedure and faulty technique. Clinical presentation depends on

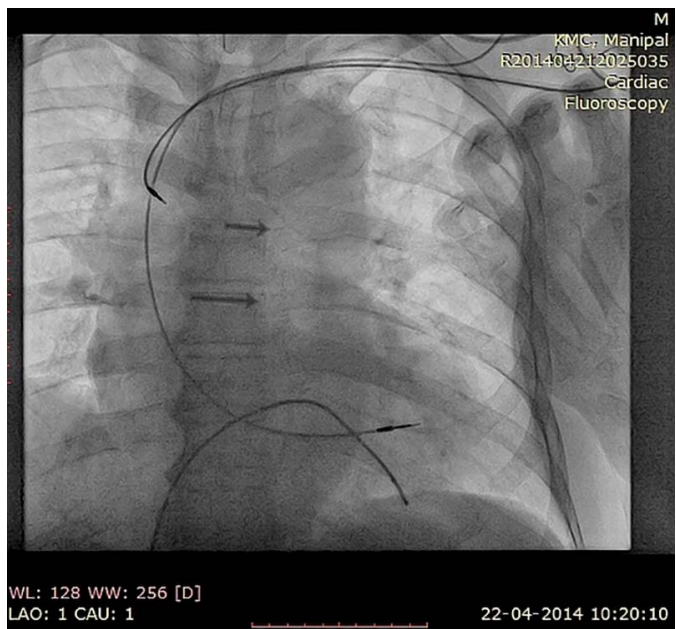

Figure 1 Fluoroscopic picture demonstrating the endocardial lead in right ventricle and air in the main pulmonary artery (arrow mark).

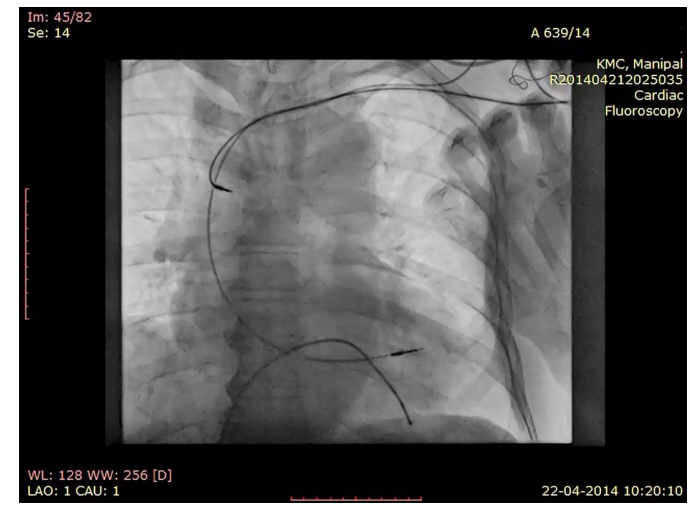

Video 1 Fluroscopic examination showing air in the main pulmonary artery. The opening and closing of the pulmonary valve also can be appreciated.

amount of air embolised, as much as $300 \mathrm{cc}$ air in venous system may result in death. ${ }^{1}$ The condition can easily diagnosed with simple fluoroscopic examination. Treatment usually is placing the patient in left lateral decubitus position and 100\% $\mathrm{O}_{2}$ for resorption of air. ${ }^{2}$ Another simple technique which can be used to minimise the air embolism is by closing the neck of the sheath with two fingers after removal of sheath stylet till the introduction of the endocardial lead (figure 3).

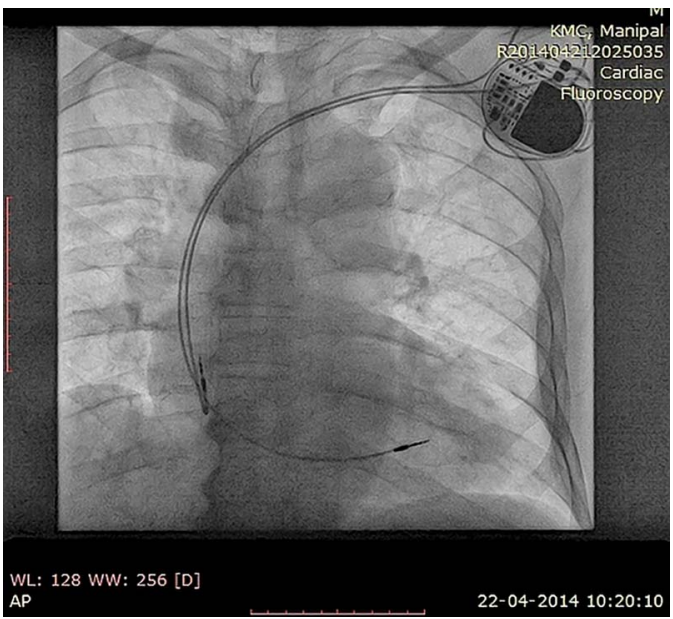

Figure 2 Postprocedure fluoroscopic picture showing two leads in right atrium and right ventricle and the pulse generator. The air in pulmonary artery has been completely resorbed. 


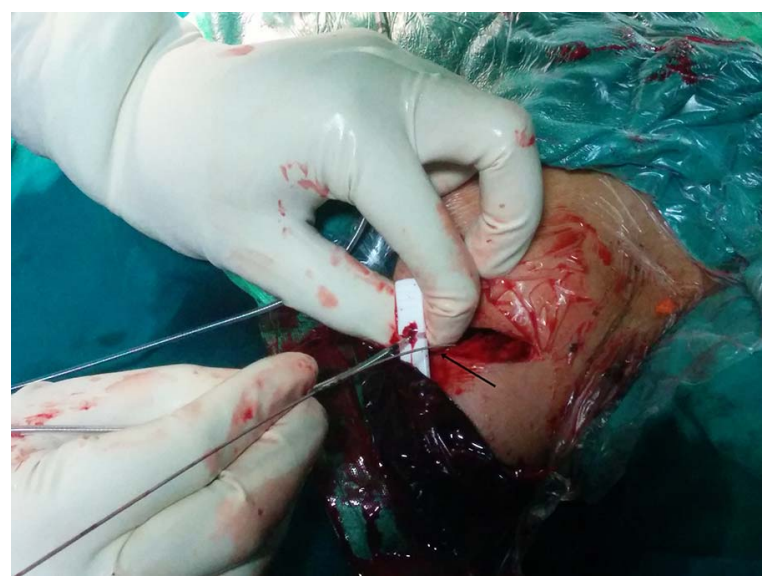

Contributors NCGS, PR, GV and JM were involved in the concept, design, definition of intellectual content and literature search. NCGS and JM were involved in data acquisition. NCGS, GV and JM were involved in the preparation, editing and review of the manuscript. NCGS, PR and GV were involved in clinical care of the patient.

Competing interests None.

Patient consent Obtained.

Provenance and peer review Not commissioned; externally peer reviewed.

\section{REFERENCES}

1 Gottlieb JD, Ericsson JA, Sweet RB. Venous air embolism: a review. Anesth Analg 1965;44:773-9.

2 Oppenheimer MJ, Durant TM, Lynch P. Body position in relation to venous air embolism and the associated cardiorespiratory changes. Am J Med Sci 1953;225:362-73.

Figure 3 Technique to minimise air embolism during lead insertion, pressing the neck of the sheath (arrow mark) once stylet is removed till the introduction of the lead.

\section{Learning points}

Air embolism is a lethal, but preventable complication.

- General predisposing factors are chronic obstructive airway disease, repeated bouts of cough during procedure and faulty technique.

- Simple to diagnose and simple to treat, but index of suspicion should always be present in any case of sudden cardiorespiratory collapse during the procedure.

Copyright 2014 BMJ Publishing Group. All rights reserved. For permission to reuse any of this content visit http://group.bmj.com/group/rights-licensing/permissions.

BMJ Case Report Fellows may re-use this article for personal use and teaching without any further permission.

Become a Fellow of BMJ Case Reports today and you can:

- Submit as many cases as you like

- Enjoy fast sympathetic peer review and rapid publication of accepted articles

- Access all the published articles

- Re-use any of the published material for personal use and teaching without further permission

For information on Institutional Fellowships contact consortiasales@bmjgroup.com

Visit casereports.bmj.com for more articles like this and to become a Fellow 